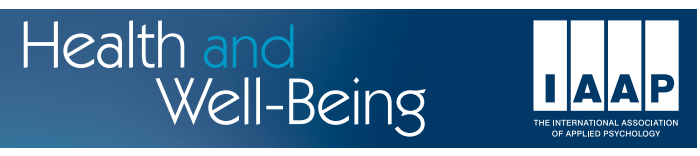

APPLIED PSYCHOLOGY: HEALTH AND WELL-BEING, 2011, 3 (3), 304-321

doi:10.1111/j.1758-0854.2011.01055.x

\title{
Well-being, Reasonableness, and the Natural Environment
}

\author{
Rachel Kaplan* and Stephen Kaplan \\ University of Michigan, USA
}

\begin{abstract}
This Special Section features a number of perspectives on the vital role played by natural environments. The three empirical papers, using different approaches and measures, representing diverse populations in different countries, and different kinds of natural settings, all provide evidence for the importance of nature to human well-being. This paper presents the Reasonable Person Model (RPM) as a framework for understanding how the environment can help bring out the best in people. Demographic and regional variations notwithstanding, people are empowered by opportunities to make a difference and be respected, they are concerned with being effective, and their efforts are guided by their mental models. Having nature nearby, even if modest in scale, can be particularly beneficial in offsetting some of the consequences of depleted attentional resources which readily undermine reasonable behavior. We focus on some important distinctions between psychological restoration (and its relationship to the effectiveness domain of RPM) and environmental preference (and its connection to RPM's model building domain). Today's all too pervasive unreasonableness is costly in terms of personal and social well-being. Understanding the vital capacity of the natural environment can make a substantial difference in bringing out the best in people.
\end{abstract}

\section{INTRODUCTION}

The papers in this Special Section have as a common theme not only that the environment matters to well-being, but that the natural environment plays a key role. Furthermore, though the particular natural environments vary widely, in each of the papers the context is nearby, everyday nature. None of these are nature showpieces or otherwise notable. Despite their relative ordinariness and limited spatial scope, however, these settings are shown to provide a wide range of psychological benefits.

As their bibliographies amply demonstrate, these papers are part of a far-reaching and fast-growing body of research that substantiates the

* Address for correspondence: Rachel Kaplan, School of Natural Resources and Environment, University of Michigan, 440 Church St., Ann Arbor, MI 48109-1041, USA. Email: rkaplan@umich.edu 
importance of the natural environment to human well-being. The papers include natural settings in different countries and concern diverse populations. They also rely on many empirical approaches and incorporate a multitude of psychological outcomes.

In this paper we present a conceptual framework-the Reasonable Person Model (RPM) - that places well-being and the role the natural environment plays in a larger context. We use the notion of reasonableness, rather than well-being, as a way to tackle the larger realms of lives that can be satisfying and meaningful. As we use it, reasonableness focuses on bringing out the best in people. It is readily undermined by the many environmentscircumstances and contexts - that hinder meeting human needs. These human needs have commonalities despite the many differences that distinguish members of our species. They constitute the three domains of RPM: to build mental models, to act meaningfully, and to be effective. Well-being is thus at the mercy of both the reasonableness of other people and many aspects of the environment.

In the next section we explore RPM in terms of its three interrelated domains. With RPM as the context, we then examine some of the roles played by the natural environment. The final section relates these themes to the other papers in the issue.

\section{THE REASONABLE PERSON MODEL}

As we are a species with immense dependence on information and a highly developed capacity for processing information, it is hardly surprising that central to reasonableness is addressing ways to meet informational needs. RPM is cast in terms of three of these - building mental models, engaging in meaningful action, and being effective. While each is important in its own right, they are interdependent and intertwined. Before characterising each of these domains, it may be useful to discuss the centrality of information.

\section{Information}

Long before the "information age" appeared on the scene, humans already depended on information. Information is ubiquitous. It was central to human life even before language was written. It is the basis of perception, cognition, emotion, and communication. We gather it through all sense modalities, share it endlessly, and guard it closely. We can't live without it, but are readily impaired by its abundance. Information and its management are thus fundamental to human well-being. Considering ways that the environment can bring out the best in people requires understanding the role of information in human effectiveness. 
The wonders of modern technology have placed huge amounts of information at our disposal quickly. However, the usefulness and availability of that information are dependent on vast amounts of information that we store and carry around without such technology. The ability to recall, to use a cell phone, to understand a conversation, to think and plan, all depend on our mental maps. These cognitive structures are the product of a great deal of prior information processing. The care and feeding of these mental maps is a crucial aspect of life, and of reasonableness (S. Kaplan \& Kaplan, 2009).

While we depend on the information that surrounds us, we can also be seriously handicapped by its excess (Klingberg, 2009). The costs of being overwhelmed by information and its demands can also impinge on reasonableness, with consequences to the individual as well as many others.

RPM organises the array of human informational needs into three main domains not only for ease of grasping the framework, but also because it can be helpful to consider the separate implications of the domains (Figure 1). In the final analysis, however, the separation of the domains is not as important as the recognition that these themes must work jointly and each is closely interrelated with the others. The rest of this section provides a brief overview of each of these domains and their interdependencies.

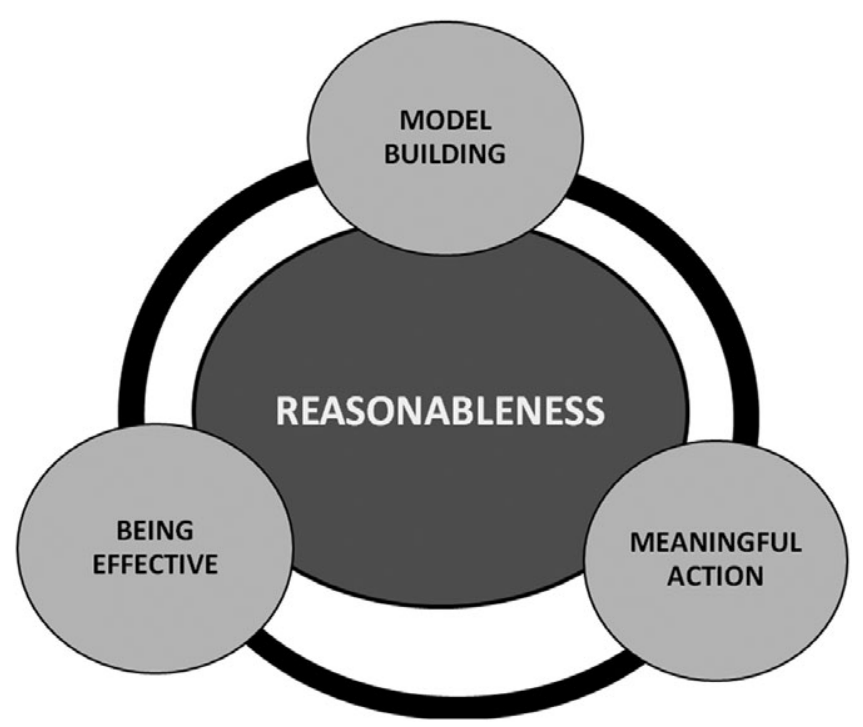

FIGURE 1. The Reasonable Person Model.

(C) 2011 The Authors. Applied Psychology: Health and Well-Being (C) 2011 The International Association of Applied Psychology. 


\section{Building Mental Models}

Mental models are a key tool not only in human survival, but in bringing out the best in people. Our mental models influence perception of what is going on and guide our actions. They enable efficient storage of vast amounts of information, prediction of what might happen next, and evaluation of potential consequences (S. Kaplan, 1973).

The dependence on mental models for human functioning would further suggest that people care deeply about information that enables the creation and maintenance of these models - making perception, cognition, and affect interdependent. If information is so central to human functioning, it is understandable that humans actively seek information and are often upset when such quests lead instead to confusion.

Thus the vital role of mental models in bringing out the best in people can be undermined by the ways in which information is provided. While there are certainly intentional efforts that reduce access to and understandability of information, far more often the impediments to building mental models are inadvertent. To the perpetrators of the confusion the consequences of their efforts are usually invisible; when we are at the receiving end, however, we are more likely to be aware of how difficult building useful models can be. Consider the imbalance between getting usable instructions and providing them. The differences between talking and listening are often reflected in the temptation to tell others all that we know as opposed to considering their need to explore options on their own terms.

Obstacles to using one's mental models can readily trigger unreasonable behavior. Confusion, lack of clarity, and obstructions to accessing information deemed important can all lead to undesirable behavior. At the same time, this can be a two-way street; seemingly unreasonable people can become cooperative when it turns out that their mental models can guide them effectively. In particular, the opportunities that enhance understanding and permit exploration of possibilities are essential for constructing and correcting mental models. In other words, often the conditions or circumstancesthe environment - are central to fostering reasonableness.

\section{Meaningful Action}

Reasonableness is also readily undermined by a sense of futility and helplessness. People are sensitive to the many instances in which their efforts are foiled, shunned, or ignored. They can be far more reasonable when they feel listened to and respected, even if their wishes are not met (Emery, Mathews, \& Kitzmann, 1994, as cited by Miller, 2001, p. 531). The sense that one is making a difference can go a long way toward bringing out the best in people.

Meaningful action can thus be exercised at many scales and take many forms. The vast number of hours contributed by millions of people to 
volunteer efforts exemplifies people's need to make a difference. Hawken's (2007) book, Blessed unrest, provides vivid imagery of this global trend and eloquently captures its significance in the book's subtitle: How the largest movement in the world came into being and why no one saw it coming. Many other forms of participation take far less time and effort than volunteering, but also speak to people's need to make a difference. Voting, for instance, may only take a moment, yet has enabled the preservation of thousands of acres of natural lands (as evidenced by the LandVote data base maintained by the Trust for Public Land).

Meaningful action and model building are often mutually facilitating. Meaningful action is helped by understanding what a situation entails. At the same time, however, the process of participating in an activity can provide opportunities for exploration that facilitate development of mental models. Similarly, efforts to make a difference can be undermined by the way information is provided, leading to confusion and a sense that one's input is not genuinely valued.

\section{Being Effective}

"Stressed out" has become common parlance. It readily connotes a state that is antithetical to feeling that one is effective. With the many demands of life increasing its frequency, what is termed stress seems known to demographic and age groups across many cultures. Unbeknownst to many of the sufferers, however, many efforts to alleviate the presumed stress may actually exacerbate it.

From the perspective of RPM, feeling "stressed out" is impacted by information. It is not, however, the direct outcome of the amount of information surrounding us. Sitting in a library can be a calming experience even though one is in the midst of vast amounts of information. There is also a great deal of information in a flowering meadow with its many colors, textures, and varied species. Rather, what leads to the negative state often subsumed by "stressed out" is likely to be the cumulative effect of information that demands concerted attention. As Simon (1971) recognised decades ago, attention is a scarce resource. The overuse of one's attentional capacity is a debilitating consequence of informational demands, causing what is commonly called mental fatigue.

Attention Restoration Theory (ART; S. Kaplan, 1995, 2001) explains how mental fatigue is the result of the depleted capacity to direct one's attention and how that scarce resource can be replenished. The cumulative effect of the effort entailed in directing attention can lead to such symptoms as irritability, impatience, and distractibility. Recovering from this fatigued mental state is facilitated by settings and activities that, rather than requiring that one pay attention, draw on a kind of attention that is effortless. This kind of attention 
comes in many forms and at varying scales. In particular, we distinguish between "hard" and "soft" fascination (R. Kaplan \& Kaplan 1989). The "hard" fascinations often entail fast motion, loud noises, and other strong stimulus patterns. They "capture" our attention and require little willpower, but at the same time may be distracting and conflicting in their impacts. As such they may add to mental fatigue rather than permit its recovery (S. Kaplan \& Berman, 2010).

By contrast, soft fascinations do not overwhelm or dominate attention, permitting the mind to wander, reflect, and recuperate. Though natural settings are not unique in offering soft fascination, they readily provide it - clouds, sunsets, motion of leaves in the breeze, the waves in the ocean, the antics of squirrels. A great deal of research (as discussed in the other papers in this issue) has shown that natural environments have a great propensity to offer soft fascination and can thus help one recover from mental fatigue. Recovery from mental fatigue is thus facilitated by some kinds of places and activities that permit one's limited capacity to direct attention to rest.

Mental fatigue is pervasive in its ramifications. Excessive or confusing information that requires attention makes it more difficult to build mental models. The lack of clear-headedness, in turn, can exacerbate efforts to tune in and participate fully. Mental fatigue may also arise from prolonged needs to be attentive, a situation many caretakers confront. While such situations may offer substantial meaningful action, they may come at the great cost of mental clarity. The satisfactions from being helpful may also make it more difficult to realise the gradual depletion of attentional capacity.

The three domains of RPM - building mental models, meaningful action, and being effective - are, thus, strongly interrelated (Figure 1). They are also all highly contextual. In other words, environments - situations, contexts, and circumstances - can serve to reduce reasonableness as well as to foster it.

\section{THE NATURAL ENVIRONMENT IN THE CONTEXT OF RPM}

Let us now turn to the specific context of natural environments. The three other papers in this issue and numerous sources elsewhere have documented many ways in which the natural environment can play a crucial role in well-being (Frumkin, 2001; Maller, Townsend, Pryor, Brown, \& St Leger, 2005). While it is now widely assumed that natural environments are preferred, when we began to explore environmental preference over 40 years ago there were no empirical studies that spoke to this issue. As van den Berg, Koole, and van der Wulp (2003) indicate, by now "the empirical evidence for the preference for natural over built environments is strong and robust" (p. 135). The preference for nature is true not only with respect to spectacular, picture-postcard aspects of nature, but even the much more mundane "everyday nature" (R. Kaplan, 1977) or "nearby nature" (R. Kaplan, 1983). The 
research on environmental preference has spawned two lines of research and conceptualisation, both now incorporated into the RPM framework: (1) the role of understanding and exploration as essential ingredients in appreciating what preference encompasses, and (2) the contrast between two kinds of attention-directed attention and soft fascination-in appreciating why certain kinds of environments are restorative. Each of these themes has pervasive connections to the overarching goals of this issue, namely to represent diverse perspectives showing the linkages between the natural environment and psychological outcomes, and to the focus on reasonableness as an integrative approach to well-being.

\section{RPM and Environmental Preference}

While experts are presumed to evaluate environmental quality (e.g. scenic beauty, or ecosystem health) by standards that would make their assessments valid and reliable, those of us without such training are presumed to be idiosyncratic and to vary widely in our judgments. Statements such as "there is no accounting for people's tastes" or that "beauty is in the eye of the beholder" suggest that preferences are random or at least unpredictable. Research findings, however, have not supported these assumptions, nor that preferences are frivolous or whimsical. Instead, results of many studies have shown strong consistencies that suggest that a vital component of preference is the anticipation of being able to function effectively in an environment. Often without realising it, people depend on rapid assessments of what the environment - physical, virtual, or conceptual — might afford.

These insights, as well as the results from numerous studies, led us to propose the preference matrix (Kaplan \& Kaplan 1982, 1989). As Table 1 shows, the matrix is divided into the major themes of understanding and exploration, which jointly are the key components of RPM's domain of building mental models. The failure to understand can severely undermine the capacity to function effectively. People dislike being lost; they want to be able to quickly extract the information that is critical to making sense of an environment. At the same time, however, people readily become restless when things are very predictable. They yearn for new challenges and even want to

TABLE 1

Preference Matrix

\begin{tabular}{lll}
\hline & Understanding & Exploration \\
\hline $\begin{array}{l}\text { Immediate } \\
\text { Inferred }\end{array}$ & Coherence & Complexity \\
\hline
\end{tabular}

(C) 2011 The Authors. Applied Psychology: Health and Well-Being (C) 2011 The International Association of Applied Psychology. 
venture beyond their comfort zone. Thus although both the familiar and the unknown are major vectors, neither by itself is sufficient.

The matrix also differentiates between information that is immediately evident as opposed to situations that depend upon greater inference. In the context of environments, one can think of this distinction as akin to a twodimensional vs. three-dimensional space, where the depth of the scene or setting provides further information. In the case of legibility (see Table 1), understanding is enhanced by landmarks and other indications that provide reassurance that one would not only find a destination, but be able to return safely as well. Mystery, by contrast, involves cues that invite further exploration; it is conveyed by clues that suggest that more could be learned if one were to go deeper into the setting. Elements that partially obscure one's path often engage one's curiosity about what lies ahead. Many highly preferred settings in the natural environment in particular offer such a sense of mystery. The bend in the path, a brightly lit area that is partially obscured by foreground vegetation, even modest land form variations, as well as ephemeral patterns of light can all engage one's curiosity and invite one to explore further.

The top row of the matrix differentiates between the understandability achieved by coherence and the exploration that can be afforded by having complexity or richness of elements in a setting. Coherence offers a sense of predictability. An environment that is low in coherence (e.g. the proverbial jungle) would be difficult to make sense of; to a novice it would be hard to quickly distinguish the salient components. An environment that is low in complexity (e.g. a wide open field), by contrast, lacks diversity, giving the sense that there is nothing to explore. Both qualities are important; the lack of either may reduce preference, but it can be easy to confuse their separate contributions. For example, a highly coherent environment may not be preferred if it lacks complexity. Characterising it as boring, however, is attributable to the low complexity, rather than the assumption of too much coherence. Similarly, lower preference for a setting that appears to be "messy" might (erroneously) be attributed to too much complexity. If the same elements were organised in a more coherent way, however, the preference may be substantially increased with no change in complexity.

What these descriptors suggest is that preference, rather than being a whim, is intimately connected to one's sense that one can function capably and effectively. The descriptors offer a variety of ways in which clarity and predictability can be increased and thus enhance a sense that one could venture safely. While offering useful insights for making environments more supportive of people's needs, the preference matrix cannot account for all aspects of environmental - or nature - preference. In particular, we should highlight the role of experience and the importance of particular natural elements in environmental preference. 
Both understandability and exploration are necessarily influenced by experience. After all, the mental models we carry with us result from experiences. Our familiarity with different kinds of environments is not only the result of previous exposures but has a persistent effect on how we perceive new settings and affects our comfort with them. Thus what appears to some people to be boring (a wetland perhaps) or messy (possibly a naturalistic landscape) may be greatly preferred by others (R. Kaplan, 2011). For those who are familiar with such settings, they can be epitomised not only by their coherence and complexity, but may also be highly legible and rich in mystery. Therefore, we would expect that familiarity can have a strong influence on preference since the prediction of being able to function effectively is strengthened by experience. However, the conclusion to be drawn here is not that familiarity will necessarily increase preference; that relationship is far more complex! "Familiarity breeds contempt" and "absence makes the heart grow fonder" express opposite relationships between these two dimensions. There are well known places that one dislikes as well as unknown places one yearns to see.

The preference matrix also does not speak to the strong attraction of particular natural features. In the natural environment water and trees are often such compelling features. Here too it is not the case that the presence of water or trees of any size or condition will necessarily be preferred (R. Kaplan, 1977). Consider, however, the contexts where the availability of water - ocean view, lakeside, pond, brook, stream - is a featured attraction often with economic implications. Research findings have often shown that trees play a vital role in preferred settings (R. Kaplan, 1983). Even a single tree can make a substantial difference in people's physical (view out of the window) and psychological outlook.

Summary. Many factors impact preference for natural settings. Familiarity is essential for developing mental models. In settings where familiarity is lacking it is thus particularly important to have supportive cues that facilitate understanding and exploration. The preference matrix offers a framework for considering such cues. Strongly preferred (and highly familiar) natural elements such as trees and water can further enhance the impact of each of the predictors subsumed by the matrix.

\section{Psychological Restoration}

Our early research on environmental preference led to the realisation that preferences, rather than being a matter of taste, can reflect people's anticipation of the ability to function effectively. Later research also helped us understand the role environments (and natural environments in particular) can play in psychological restoration - or the recovery from mental fatigue. As discussed earlier, environments or activities that are restorative are based on 
ways to offset directed attention with the more effortless, less concerted kind of attention. The emphasis is thus not on the preference indicators, but rather on ways to foster clear-headedness. The fact that preferred environments can also be restorative (Galindo \& Hidalgo, 2005; Ivarsson \& Hagerhall, 2008; van den Berg, Hartig, \& Staats, 2007) is hardly surprising. It is important to recognise, however, that these are separate considerations. In other words, preferred environments may vary in their degree of restorativeness and some settings may be restorative even if they are not particularly preferred.

The all too common confusion between preference and restoration can lead to misleading assumptions and to misguided research strategies. People readily judge what they like or dislike and depend on these judgments for many decisions. By contrast, recognising what is, or may be, restorative is far more difficult. If people were more cognisant of the costs of expending directed attention, quite possibly feeling "stressed out" would be less prevalent. In other words, the lack of sensitivity to the need for restoration and to ways of achieving it can (and often does) lead to detrimental consequences.

Many activities that are ubiquitous for "chilling out" (or regaining some attentional capacity) may not serve their intended purpose. Cruising the Internet can offer endless entertainment. Comparably for many people of all ages watching television is a common venue for what is mistakenly assumed to be restorative. However, there is reason to think that these pursuits are counterproductive if clear-headedness is the desired goal (S. Kaplan \& Berman, 2010). Herzog, Chen, and Primeau's (2002) findings contrasting what study participants would advise a friend to do when needing a break, and what they would do themselves under the same circumstances, are informative. On the other hand, it is probably not unusual for people to differ in the advice they give others and what they follow themselves.

In fact, many cultural patterns run counter to taking note of declining attentional capacity and ways to compensate for steady demands on one's attention. Productivity and maximising effort are encouraged, signs of mental fatigue (e.g. error proneness, irritability, mind wandering) are often attributed to other causes, and activities that would permit recovery are generally taboo in the workplace. Taking naps or walks several times during the work day is a "luxury" not afforded many employees (perhaps pointing to some benefits of telecommuting).

The extensive research showing the positive role that the natural environment can play in well-being offers a rich assortment of applicable guidance. While many kinds of settings can serve to replenish the depleted attentional capacity, the literature supports the strong role played by the natural environment (Abraham, Sommerhalder, \& Abel, 2010; Frumkin, 2005; Pretty, 2004; Velarde, Fry, \& Tveit, 2007). In particular, studies based on large-scale random samples (e.g. Stigsdotter et al., 2010) have shown that the proximity of the natural environment is significantly related to quality of life and stress. 
Findings with respect to green exercise - physical exercise in the natural environment (Barton \& Pretty, 2010; Maas et al., 2009) — document the vital role that active engagement in nature can play in countering many endemic health concerns, including obesity, diabetes, and heart disease. The opportunities for green exercise, however, may be minimal or absent for many urban residents and for individuals with long commutes who may also not leave their workplace during the entire day.

The availability of natural elements, however, can also serve vast numbers of people where they spend most of their waking hours, namely indoors. We do not know of any documentation of the extent to which natural elements are accessible to people in their viewshed at work, school, home, or other places where so much time is spent. It is fair to guess, however, that such documentation would reveal widespread deficits. Yet the literature on the impacts such nature availability can play has shown a great diversity of potent benefits. Velarde et al. (2007) provide an analysis of 31 empirical articles which show health effects of landscape views. The studies we mention here include a wide range of environmental contexts with the common characteristic that they are based on long-term patterns as opposed to situations involving relatively short duration in the particular environment (as is true of a hospital stay). Furthermore, none of these studies depend on the participants' perception of restoration.

Moore's (1981) study is particularly informative both because of the reason for the long-term contact with nature (namely, the view from the cell of a very large prison) and the outcome variable that was used (frequency of the prisoners' sick-call visits). The prisoners who viewed other prison cells across the courtyard had a substantially higher rate of using medical services than those with a view of the farmfields surrounding the penitentiary.

Matsuoka's (2010) study, based on 101 high school campuses, showed a consistent relationship between views that provide nature exposure and measures of student performance and behavior. "Specifically, views with greater quantities of trees and shrubs from cafeteria as well as classroom windows are positively associated with standardised test scores, graduation rates, percentages of students planning to attend a four-year college, and fewer occurrences of criminal behavior" (p. 273).

Tennessen and Cimprich's (1995) study was also carried out in the context of campus building windows, but their participants were residents of a university dormitory. In this study also, greater amount of vegetation in the view was linked to better academic achievement and mental functioning.

In the workplace context, R. Kaplan (1993) found that having natural elements in the view related positively to employees' satisfaction with the view which, in turn, was a strong predictor of their perception of being less frustrated and more patient, more challenged and enthusiastic about their jobs, and generally more satisfied with their situations. In many cases study 
participants reported that they are less error-prone or impulsive, clearer in what they need to do, and better able to focus - all important to feeling less muddled and more capable.

Kuo, Sullivan, and their colleagues carried out several studies in the context of a public housing project, examining the role played by the availability of a few trees and lawn adjacent to the high-rise dwellings. The range of benefits evidenced by this paucity of available nature is dramatic. They include more social interaction among youth and adults (Coley, Kuo, \& Sullivan, 1997), greater sense of community among older adults (Kweon, Sullivan, \& Wiley, 1998), greater feeling of safety (Kuo, Sullivan, Coley, \& Brunson, 1998), less aggressive and violent behavior (Kuo \& Sullivan, 2001a), and less impulsivity and irritability (Kuo \& Sullivan, 2001b). A study by Faber Taylor, Kuo, and Sullivan (2002) showed that for inner city girls the amount of nature in the view accounted for greater self-discipline.

From the perspective of RPM, these varied social and psychological benefits relate closely to the Being Effective domain. They also provide insights into the interrelatedness of the domains: having a clear head can facilitate being engaged in other activities as well as exploration and understanding (e.g. better school performance). The findings from these diverse studies thus help us understand the multiple aspects of well-being and reasonableness that derive from the nearby natural environment.

\section{RPM AND THE SPECIAL SECTION}

The three empirical papers comprising the rest of this special section provide further evidence of the many dimensions of well-being that are supported by the natural environment. Ward Thompson and Aspinall (2011) report that elderly people with access to a local park (within 10 minutes from home) are not only "twice as likely to engage in walking, but also twice as likely to be satisfied with life". Ward Thompson's OPENspace research further shows that the attraction of the natural environment and the perception of the benefits it provides are more salient factors in mental well-being and psychological restoration than the walking per se. Using a variety of measures the Johansson, Hartig, and Staats (2011) study shows relationships to well-being both in terms of setting (park vs. urban street) and with respect to the social context (alone or with a friend) of a prescribed walk. Higher ratings of tranquillity and lower sense of time pressure were found in the park setting; ratings of physical exhaustion were higher when walking alone in either setting. Compared to scores before the walk, ratings of revitalisation and positive engagement were consistently higher after the walk in all instances other than when walking alone in the urban setting. The Faber Taylor and Kuo (2011) study, based on survey responses by parents or legal guardians of children suffering from Attention-Deficit Hyperactivity Disorder (ADHD), shows a relationship 
between time typically spent in natural areas and lower symptom severity. Their findings are likely to have implications for a number of issues related to well-being, including clear-headedness and sense of competence.

This brief overview of some of the findings shown in the three empirical papers in this issue illustrates the diversity of health-related indicators and well-being measures that have been characteristic of the growing literature in this area. That literature is also noteworthy for encompassing many kinds of natural environments that have in common that they are generally unspectacular, nearby, and often of modest spatial extent. Furthermore, the contact with the natural environment may be relatively brief (such as a neighborhood walk) or even indirect (e.g. the view from the window). Here again, the three studies exemplify these patterns.

The Johansson et al. research is based on a specific municipal park, described as following along a river and including among other features "an allée of hardwood trees in a landscaped area with bushes and grass", some recreational areas, and a large open field. The study compares this setting to a specified route in a more urban context, along city streets, with each of the 20 Swedish student participants walking in each setting both alone and with a friend.

While walking was the sole activity in the Johansson et al. work, Ward Thompson and Aspinall's paper discusses several studies carried out in England and Scotland. Collectively these studies draw on a variety of activities in diverse nearby public natural sites, including local woodlands, parks, and other green open spaces. Particularly noteworthy in this paper is the authors' focus on perceptions of the natural environment as well as their physical qualities. They rightly note that objective and subjective measures of the environment may be quite different, yet "ultimately these perceptions ... play a role in people's responses and behavior". The paper also differs from the others in the diversity of populations that are discussed, including residents of deprived communities, different ethnic groups, and the elderly.

The natural environments in the Faber Taylor and Kuo study are portrayed in terms of broad categories with some supported by a single prototypic photo. Survey participants (i.e. parents or legal guardians of ADHD children) were asked to select the category characterising where the "description sounds most like where your child played most of the time after school and on the weekends during the past week". Of the four categories most frequently chosen, two represent natural settings: "places where there are big trees and grass" and "places where there is a lot of open grass". Since the participants responded to a survey posted on the website of Children and Adults with Attention-Deficit/Hyperactivity Disorder the particular natural settings could be in public or private (e.g. backyards or front lawns) contexts and could vary greatly across geographic areas represented by the respondents. While the paper does not address the activities carried out in these 
settings, the authors report that for the hyperactive children it was the places with "a lot of open grass" (and not those with big trees) that were related to less severe symptoms.

The studies provide useful indications of the restorative qualities of natural environments. Two of the studies relate their work to Attention Restoration Theory (Johansson et al. and Faber Taylor and Kuo) and two (Johansson et al. and Ward Thompson and Aspinall) specifically mention outcomes related to clear-headedness: the ability to relax or "unwind", peace and quiet, feeling less time pressure, and greater sense of tranquillity.

None of the studies directly addresses the other two domains of RPM. It is interesting to consider, however, whether the social context studied by Johansson et al. has ties to exploration and understanding. This could depend on the nature of the conversation while walking. Walking with someone else could lead to being absorbed in unrelated conversation or to greater engagement with the environment (Duvall, 2010, 2011). The discussion could, for example, entail observations of architectural details, what is in the storefronts, the ripples in the water, or the shadows cast by the rows of trees. Such conversation could accrue to the restorative nature of the walk as well as the RPM model building domain. Social patterns are not discussed in either of the other two papers but could play a role in these contexts as well. In the Faber Taylor and Kuo study, children's play is often with others and likely to be influenced by the kind of environment that is available. In the context of Ward Thompson and Aspinall's WIAT study, social patterns are expressed by the residents' greater engagement in countering safety concerns seen as a barrier to walking. Such meaningful action can lead to changes that make the local environment more attractive and supportive of desired activities.

\section{CONCLUSION}

There is no doubt that across the globe humans have contributed to vast amounts and reaches of environmental decline and degradation. To some people the focus on ever-deteriorating patterns readily casts the environment in negative terms (R. Kaplan and Kaplan, 2011). A major contribution of this special section is to look more closely at the vital positive impacts that the environment plays in human well-being. Such positive dimensions can be found in many environmental contexts; they are, however, surprisingly consistent where there are natural elements. Yet the "nature" that makes such a strong difference need not be extensive or awesome. The studies included here provide strong support for the powerful role the everyday, nearby natural environment can play.

These strong positive influences afforded by access to nearby nature have been shown across the age spectrum, for many nationalities, and regardless of economic means. Nearby parks can provide it, but so can 
trees along residential streets, or the view of a single tree outside the window. Given the many ways that the natural environment can foster well-being and reasonableness it is imperative that nature is available nearby in the urban context.

The urban context is particularly fraught with demands on attentional resources. It is also the context where reasonable behavior is made more vulnerable. RPM is offered as a framework that posits that reasonableness is intimately related to the possibilities for understanding and exploration, for being respected and afforded possibilities for participating toward meaningful goals, and for opportunities to achieve clear-headedness and for enhancing one's competence. Environments play a central role in making these goals viable. In particular, the availability of nearby, accessible nature can contribute substantially to well-being.

Not only can nearby nature be influential with respect to well-being; it also provides a dramatically cost-effective means of achieving well-being. There is no requirement for vast areas, for pristine nature, for manicured gardens, for expensive maintenance. The amount of requisite nature can be modest in physical and temporal scales, but it needs to be readily available. The attentional costs of life's demands can accrue rapidly; opportunities to be in nature or to view it can help to offset these costs. However, the perception that many settings and activities are restorative may be deceiving. Restoration is not a matter of doing what one likes to do, but of permitting one's drained attention to be replenished.

Reasonableness seems in short supply as we look about our troubled world. We need to know a great deal more about how it can be achieved and sustained. We hope this essay inspires quests for greater exploration and understanding, meaningful action, and effective approaches to attaining our common goal.

\section{ACKNOWLEDGEMENTS}

We greatly appreciate the financial support provided by the US Department of Agriculture, Forest Service Northern Research Station, over many decades. We also thank the reviewers and editors for their helpful suggestions.

\section{REFERENCES}

Abraham, A., Sommerhalder, K., \& Abel, T. (2010). Landscape and well-being: A scoping study on the health-promoting impact of outdoor environments. International Journal of Public Health, 55, 59-69.

Barton, J., \& Pretty, J. (2010). What is the best dose of nature and green exercise for improving mental health? A multi-study analysis. Environmental Science and Technology, 44, 3947-3955. 
van den Berg, A.E., Hartig, T., \& Staats, H. (2007). Preference for nature in urbanized societies: Stress, restoration, and the pursuit of sustainability. Journal of Social Issues, 63(1), 79-96.

van den Berg, A.E., Koole, S.L., \& van der Wulp, N.Y. (2003). Environmental preference and restoration: (How) are they related? Journal of Environmental Psychology, 23, 135-146.

Coley, R.L., Kuo, F.E., \& Sullivan, W.C. (1997). Where does community grow? The social context created by nature in urban public housing. Environment and Behavior, 29(4), 468-494.

Duvall, J.D. (2010). Deliberate engagement as a strategy for promoting behavior change while enhancing well-being. Doctoral dissertation. http://hdl.handle.net/ 2027.42/77879. (Retrieved 15 June 2011.)

Duvall, J.D. (2011). Enhancing the benefits of outdoor walking with cognitive engagement strategies. Journal of Environmental Psychology, 31, 2735.

Emery, R.E., Mathews, S.G., \& Kitzmann, K.M. (1994). Child custody mediation and litigation: Parents' satisfaction and functioning one year after settlement. Journal of Consulting and Clinical Psychology, 62, 124-129.

Faber Taylor, A., \& Kuo, F.E. (2011). Could exposure to everyday green spaces help treat ADHD? Evidence from children's play settings. Applied Psychology: Health and Well-Being, 3, 281-303.

Faber Taylor, A., Kuo, F.E., \& Sullivan, W.C. (2002). Views of nature and selfdiscipline: Evidence from inner city children. Journal of Environmental Psychology, $22,49-63$.

Frumkin, H. (2001). Beyond toxicity: Human health and the natural environment. American Journal of Preventive Medicine, 20(3), 234-240.

Frumkin, H. (2005). The health of places, the wealth of evidence. In P.F. Barlett (Ed.), Urban place: Reconnecting with the natural world (pp. 253-270). Cambridge, MA: MIT Press.

Galindo, M.P., \& Hidalgo, M.C. (2005). Aesthetic preferences and the attribution of meaning: Environmental categorization processes in the evaluation of urban scenes. International Journal of Psychology, 40(11), 19-26.

Hawken, P. (2007). Blessed unrest: How the largest movement in the world came into being and why no one saw it coming. New York: Viking.

Herzog, T.R., Chen, H.C., \& Primeau, J.S. (2002). Perception of the restorative potential of natural and other settings. Journal of Environmental Psychology, 22, 295-306.

Ivarsson, C.T., \& Hagerhall, C.M. (2008). The perceived restorativeness of gardens: Assessing the restorativeness of a mixed built and natural scene type. Urban Forestry and Urban Greening, 7, 107-118.

Johansson, M., Hartig, T., \& Staats, H. (2011). Psychological benefits of walking: Moderation by company and outdoor environment. Applied Psychology: Health and Well-Being, 3, 261-280.

Kaplan, R. (1977). Preference and everyday nature: Method and application. In D. Stokols (Ed.), Perspectives on environment and behavior: Theory, research, and applications (pp. 235-250). New York: Plenum. 
Kaplan, R. (1983). The role of nature in the urban context. In I. Altman \& J.F. Wohlwill (Eds.), Behavior and the natural environment (pp. 127-161). New York: Plenum.

Kaplan, R. (1993). The role of nature in the context of the workplace. Landscape and Urban Planning, 26, 193-201.

Kaplan, R. (2011). Intrinsic and aesthetic values of urban nature: A psychological perspective. In I. Douglas, D. Goode, M. Houck, \& R. Wang (Eds.), The Routledge handbook of urban ecology (pp. 385-393). London: Routledge.

Kaplan, R., \& Kaplan, S. (1989). The experience of nature: A psychological perspective. New York: Cambridge University Press. Republished by Ann Arbor, MI: Ulrich's 1995.

Kaplan, R., \& Kaplan, S. (2011). Anthropogenic / anthropogenerous: Creating environments that help people create better environments. Landscape and Urban Planning, 100, 350-352.

Kaplan, S. (1973). Cognitive maps in perception and thought. In R.M. Downs \& D. Stea (Eds.), Image and environment (pp. 63-78). Chicago, IL: Aldine.

Kaplan, S. (1995). The restorative benefits of nature: Toward an integrative framework. Journal of Environmental Psychology, 15(3), 169-182.

Kaplan, S. (2001). Mediation, restoration and the management of mental fatigue. Environment and Behavior, 33(4), 480-506.

Kaplan, S., \& Berman, M.G. (2010). Directed attention as a common resource for executive functioning and self-regulation. Perspectives on Psychological Science, 5(1), 43-57.

Kaplan, S., \& Kaplan, R. (1982). Cognition and environment: Functioning in an uncertain world. New York: Praeger. Republished by Ann Arbor, MI: Ulrich's 1989.

Kaplan, S., \& Kaplan, R. (2009). Creating a larger role for environmental psychology: The reasonable person model as an integrative framework. Journal of Environmental Psychology, 29(3), 329-339.

Klingberg, T. (2009). The overflowing brain: Information overload and the limits of working memory. Oxford: Oxford University Press.

Kuo, F.E., \& Sullivan, W.C. (2001a). Environment and crime in the inner city: Does vegetation reduce crime? Environment and Behavior, 33(3), 343-367.

Kuo, F.E., \& Sullivan, W.C. (2001b). Aggression and violence in the inner city: Effect of environment via mental fatigue. Environment and Behavior, 33(4), 543-571.

Kuo, F.E., Sullivan, W.C., Coley, R.L., \& Brunson, L. (1998). Fertile ground for community: Inner-city neighborhood common spaces. American Journal of Community Psychology, 26(6), 823-851.

Kweon, B.-S., Sullivan, W.C., \& Wiley, A.R. (1998). Green common spaces and the social integration of inner-city older adults. Environment and Behavior, 30(6), $832-858$.

Maas, J., Verheij, R.A., de Vries, S., Spreeuwenberg, P., Schellevis, F.G., \& Groenewegen, P.P. (2009). Morbidity is related to a green living environment. Journal of Epidemiological Community Health, 63, 967-973.

Maller, C., Townsend, M., Pryor, A., Brown, P., \& St Leger, L. (2005). Healthy nature healthy people: "Contact with nature" as an upstream health promotion intervention for populations. Health Promotion International, 21(1), 45-54. 
Matsuoka, R.H. (2010). Student performance and high school landscapes: Examining the links. Landscape and Urban Planning, 97, 273-282.

Miller, D.T. (2001). Disrespect and the experience of injustice. Annual Review of Psychology, 52, 527-553.

Moore, E.O. (1981). A prison environment's effect on health care service demands. Journal of Environmental Systems, 11, 17-34.

Pretty, J. (2004). How nature contributes to mental and physical health. Spirituality and Health International, 5(2), 68-78.

Simon, H.A. (1971). Designing organizations for an information-rich world. In M. Greenberger (Ed.), Computers, communication, and the public interest (pp. 37-72). Baltimore, MD: The Johns Hopkins Press.

Stigsdotter, U.K., Ekholm, O., Schipperijn, J., Toftager, M., Jørgensen, F.K., \& Randrup, T.B. (2010). Health promoting outdoor environments: Associations between green space, and health, health-related quality of life and stress based on a Danish national representative survey. Scandinavian Journal of Public Health, 38(4), 411-417.

Tennessen, C.M., \& Cimprich, B. (1995). Views to nature: Effects on attention. Journal of Environmental Psychology, 15(1), 77-85.

Trust for Public Land LandVote. http://www.tpl.org/tier3_cd.cfm?content_item_id= $12010 \&$ folder_id $=2386 /$ (accessed 15 November 2010).

Velarde, M.D., Fry, G., \& Tveit, M. (2007). Health effects of viewing landscapes: Landscape types in environmental psychology. Urban Forestry and Urban Greening, 6, 199-211.

Ward Thompson, C., \& Aspinall, P.A. (2011). Natural environments and their impact on activity, health, and quality of life. Applied Psychology: Health and Well-Being, 3, 230-260. 